\title{
Removal of Lead from Water by Electrocoagulation Applying Response Surface Method (RSM) in A Uniquely Designed Rector
}

\author{
Ulker Bakir Ogutveren, Umran Tezcan Un, and Nihal Erginel
}

\begin{abstract}
Lead is highly harmful to living organisms even in very low concentration. Lead exposure in humans can have severe neurological and physiological repercussions. The objective of this study is treatment of lead from water by electrocoagulation using iron electrodes applying RSM in an uniquely designed reactor. The evaluation of the main and interaction effects of process variables such as current density, initial lead concentration, $\mathrm{pH}$ and $\mathrm{Na}_{2} \mathrm{SO}_{4}$ concentration as a supporting electrolyte on the removal efficiency of lead were analyzed applying RSM. The levels of the factors were determined with variance analysis and found to be 10-50 $\mathrm{mAcm}^{-2}$ with the increments of 10 units for current density, $50-250 \mathrm{mgL}^{-1}$ with the increments of 50 units for initial lead concentration, 3-7 with the increments of 1 units for $\mathrm{pH}$ and 0.01-0.09 molL $^{-1}$ with the increments of 0.02 units for $\mathrm{Na}_{2} \mathrm{SO}_{4}$ concentration.
\end{abstract}

As a result of study, it was found that current density has a linear effect while current density and initial $\mathrm{pH}$ have quadratic effects on the removal efficiency. Lead removal efficiency reach a maximum value of $98.76 \%$ when the current density was 40 $\mathrm{mA} / \mathrm{cm}^{2}$ and initial $\mathrm{pH}$ was 4.7 .

Index Terms-Electrocoagulation, iron electrode, lead removal, response surface method.

\section{INTRODUCTION}

The global industrial revolution has led to an unprecedented dissemination of toxic substances in the environment. Exposure to these pollutants especially through dietary intake of plant-derived food and beverages, drinking water, or air can have long-term effects on human health [1]. For example, long-term exposure to lead in humans can cause acute or chronic damage to the nervous system, while long-term exposure of cadmium in humans is associated with renal dysfunction and obstructive lung disease and has also been linked to lung cancer and damage to human's respiratory systems [2].

Different industrial wastes, particularly such as those from mining, electro-plating, lead smelting and metal-finishing industries, waste storage and treatment, chemical manufacturers, etc., discharge significant amounts of heavy

Manuscript received April 5, 2018; revised May 24, 2018. This project was supported by Anadolu University Scientific Research Project Commission under Grant (1404F242).

U. Bakir Ogutveren is with the Center for Applied Environmental Research, Anadolu University, Eskisehir, Turkey (e-mail:uogutveren@anadolu.edu.tr).

U. Tezcan Un is with Department of Environmental Engineering, Anadolu University, Eskisehir, Turkey (e-mail: utezcan@ anadolu.edu.tr).

N. Erginel is with Department of Industrial Engineering, Anadolu University, Eskisehir, Turkey (e-mail: nerginel@ anadolu.edu.tr). metals both in elemental and compound (organic and inorganic) forms. Since heavy metals cannot be degraded or destroyed, they persist in the environment. These metals are lead $(\mathrm{Pb})$, cupper $(\mathrm{Cu})$, tin $(\mathrm{Sn})$, silver $(\mathrm{Ag})$, nickel $(\mathrm{Ni})$, chrome $(\mathrm{Cr})$, mercury $(\mathrm{Hg})$, cadmium $(\mathrm{Cd})$, iron $(\mathrm{Fe})$, cobalt (Co), arsenic (As).

Lead is of particular interest because of its toxicity and its widespread presence in the environment. Lead is used in accumulator and battery production and is one of the most toxic metals besides $\mathrm{Cd}$ (cadmium) and $\mathrm{Hg}$ (mercury). Maximum allowable dosages are $0.00003 \mathrm{mg} / \mathrm{L}$ for mercury, $0.01 \mathrm{mg} / \mathrm{L}$ for cadmium and $0.006 \mathrm{mg} / \mathrm{L}$ for lead. Lead is highly harmful to living organisms even in very low concentration. Lead exposure in humans can have severe neurological and physiological repercussions. Because these symptoms may occur slowly, lead poisoning can be easily overlooked [3].

Removal of lead from industrial processes can be classified into several categories. Some of the most effective methods to remove lead from contaminated water are precipitation, stabilization, ion exchange, and adsorption. Electrocoagulation is an emergent technology and has proven its viability by removing a wide range of pollutants.

Electrocoagulation introduces metal cations in situ, electrochemically, using sacrificial anodes like aluminum or iron inside a reactor. Oxidation of iron in an electrolytic system produces iron hydroxide, $\mathrm{Fe}(\mathrm{OH}) \mathrm{n}$, where $\mathrm{n}=2$ or 3 , which are highly charged coagulants adsorbing pollutants and forming insoluble floc particles. According to Mollah et aş, two mechanisms have been proposed for the production of $\mathrm{Fe}(\mathrm{OH}) \mathrm{n}$; one of them was shown in reactions 1-4 and more details have been given elsewhere [4].

Anode:

$$
\begin{gathered}
4 \mathrm{Fe}_{(\mathrm{s})} \rightarrow 4 \mathrm{Fe}_{(\mathrm{aq})}^{2+}+8 \mathrm{e}^{-} \\
4 \mathrm{Fe}_{(\mathrm{aq})}^{2+}+10 \mathrm{H}_{2} \mathrm{O}+\mathrm{O}_{2(\mathrm{~g})} \rightarrow 4 \mathrm{Fe}(\mathrm{OH})_{3(\mathrm{~s})}+8 \mathrm{H}^{+}
\end{gathered}
$$

Cathode:

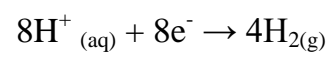

Overall:

$$
4 \mathrm{Fe}_{(\mathrm{s})}+10 \mathrm{H}_{2} \mathrm{O}+\mathrm{O}_{2(\mathrm{~g})} \rightarrow 4 \mathrm{Fe}(\mathrm{OH})_{3(\mathrm{~s})}+4 \mathrm{H}_{2(\mathrm{~g})}
$$

The advantages of electrocoagulation include high particulate removal efficiency, a compact treatment facility, relatively low cost, does not require supplementary addition of chemicals, reduces the volume of produced sludge and the possibility of complete automation [5].

In this study, the effect of different factors including current density, initial lead concentration, $\mathrm{pH}$ and $\mathrm{Na}_{2} \mathrm{SO}_{4}$ 
concentration on removal of lead from wastewater by electrocoagulation. A uniquely designed four blade impeller iron anode was used in batch mode. This paper reports on significant outcomes of the configuration and evaluates the effect of operating factors on removal efficiency of the process. An empirical model, in terms of effective operational factors was developed through Response Surface Methodology, and an optimization of operational conditions was conducted.

\section{MATERIAL AND METHODS}

\section{A. Experimental Set- $U p$}

As a stock solution lead (II) nitrate $\left[\mathrm{Pb}\left(\mathrm{NO}_{3}\right)_{2}\right]$ (Merck) was prepared with $1000 \mathrm{ppm}$ concentration. Before the experiments, stock solution was diluted to desired concentration with $500 \mathrm{~mL}$ volume. $\mathrm{pH}$ was adjusted to acidic level using $2 \mathrm{~N} \mathrm{H}_{2} \mathrm{SO}_{4}$.

EC Apparatus included three parts; DC Power supply (Statron 2257), iron special designed anode as a stirrer and iron cylindrical cathode. An iron impeller blades with holes was used as anode. It had 4 blades of height $7 \mathrm{~cm}$, width 3.5 $\mathrm{cm}$ and the thickness of the blade was $0.5 \mathrm{~cm}$. Anode surface area with 14 holes of $1.2 \mathrm{~cm}$ diameter was $94 \mathrm{~cm}^{2}$. Cathode was an iron cylinder of $10.3 \mathrm{~cm}$ in diameter and $10 \mathrm{~cm}$ at the height. Experimental set up is shown in Fig. 1. Solution was poured into cathode and stirrer was dipped into solution with $2 \mathrm{~cm}$ height from the bottom.
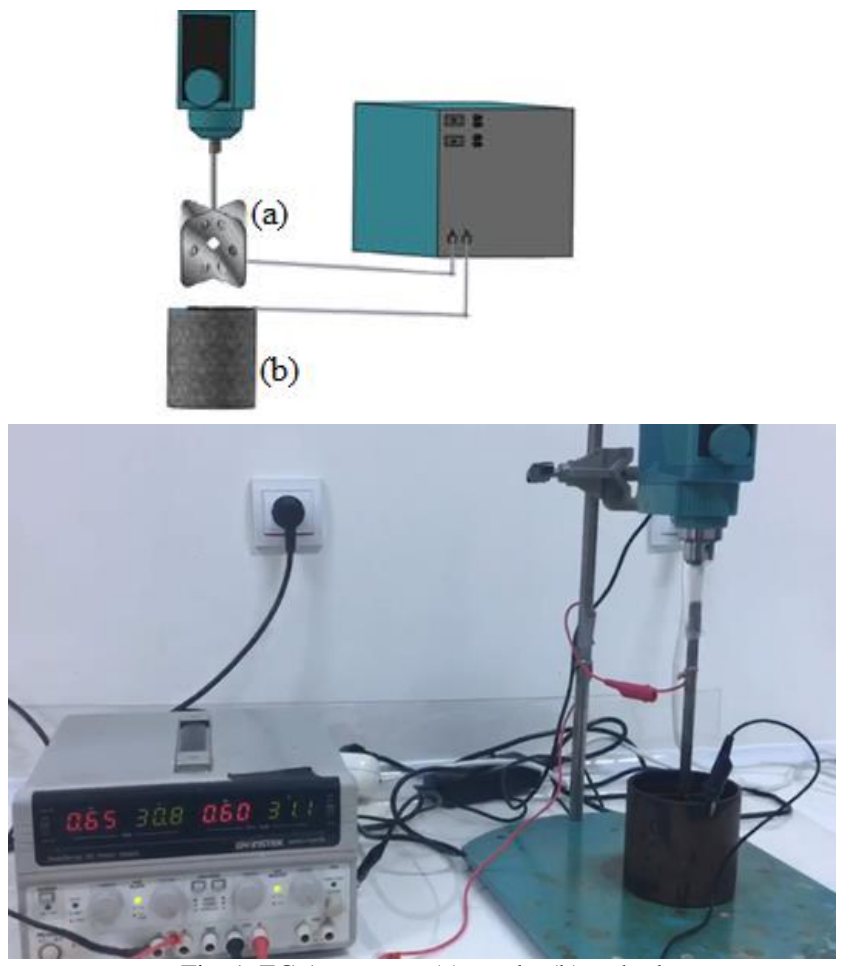

Fig. 1. EC Apparatus; (a) anode, (b) cathode.

Experiments were run 40 minutes with $50 \mathrm{rpm}$ stirring speed. Temperature, $\mathrm{pH}$ and voltage were not controlled but just monitored. $5 \mathrm{~mL}$ of samples were taken with 10 minutes interval. All samples were filtered with blue band filter paper (Whatman), then final $\mathrm{pH}$ of the samples were adjusted to $\mathrm{pH}$ 3 before analytical analysis. Lead concentration of solution was determined using Atomic Absorption Spectrophotometer
(Varian SpectrAA 250 Plus).

The removal efficiency (RE\%) after EC was calculated using equation (5)

$$
R E \%=\left(\frac{C o-C}{C o}\right) \times 100
$$

where $\mathrm{C}_{\mathrm{o}}$ and $\mathrm{C}$ are the concentrations of $\mathrm{Pb}$ before and after EC process, respectively in ppm.

All samples were analyzed in duplicate to ensure data reproducibility, and an additional measurement was carried out, if necessary

\section{B. Response Surface Method}

Response surface method (RSM) is a useful statistical technique for modeling and analyzing to research the influence of factors with many levels. When the effects of some parameters on the system performance were investigated the other parameters were kept constant in conventional experimental design methods. Thus effects of different parameters cannot be investigated at the same time in such systems. On the other hand, in RSM the effects of all parameters on the system performance can be investigated simultaneously. Therefore, this bring about some advantages such as decreasing the number of experiments, saving time and cost and using the natural sources effectively [6].

RSM, is capable of determining the interaction between the parameters, and which one is dominant in this interactivity and in the method [7]. Also RSM is an inevitable technique to show both linear and nonlinear relationships between independence variable named factors and response by setting a model that include linear and square terms, and interaction terms which represent the effects of two independent variables at the same time. RSM is used to determine the best combination and levels of factors that response near the optimum.

If there is curvature in the system, then a polynomial of higher degree must be used for two independent variables, such as the second-order model [8]. An example was given in equation (6).

$$
\hat{y}=\beta_{0}+\sum_{i=1}^{k} \beta_{i} x_{i}+\sum_{i=1}^{k} \beta_{i i} x_{i}^{2}+\sum_{i<j} \beta_{i j} x_{i} x_{j}+\varepsilon
$$

where $\hat{y}$ is the estimated response, $\beta_{0}$ is the constant, $\beta_{i}$ is the regression coefficient of $i$. independent variables, $\beta_{i i}$ shows the regression coefficient of $i$. independent variables' quadratic effects, $\beta_{i j}$ represents the coefficient of two-way interaction between $i$. and $j$. independent variable and $\varepsilon$ is the error term.

In this study, Central Composite Design, the type of RSM, is implemented was used for the design of experiments and MINITAB 17.0 method was applied for evaluating experimental data. Variable factors as effective parameters were selected as current density, $\mathrm{pH}$, initial $\mathrm{Pb}$ concentration and amount of $\mathrm{Na}_{2} \mathrm{SO}_{4}$ to be added and be assigned $X_{1}, X_{2}, X_{3}$ and $X_{4}$ respectively with codded value of levels as: $-2,-1,0$, 1,2 . Five different levels of $X_{1}: 10,20,30,40,50 \mathrm{mAcm}^{-2}$; $X_{2}: 3,4,5,6,7 ; X_{3}: 50,100,150,200,250 \mathrm{mgL}^{-1} X_{4}: 0.01$, 
$0.03,0.05,0.07$ and $0.09 \mathrm{M} \mathrm{Na}_{2} \mathrm{SO}_{4}$. These values can be seen in Table I. The central composite design with four factors and two replications are used as experimental design.

\begin{tabular}{|c|c|c|c|c|c|c|}
\hline \multirow{2}{*}{ Factor } & \multirow{2}{*}{$\begin{array}{c}\text { Original } \\
\text { Factor } \\
\text { (X) }\end{array}$} & \multicolumn{5}{|c|}{ Factor Code } \\
\hline & & -2 & -1 & $\mathbf{0}$ & 1 & 2 \\
\hline $\begin{array}{l}\text { Current Density } \\
\left(\mathrm{mA} / \mathrm{cm}^{2}\right)\end{array}$ & $\mathrm{X}_{1}$ & 10 & 20 & 30 & 40 & 50 \\
\hline Initial $\mathrm{pH}$ & $\mathrm{X}_{2}$ & 3 & 4 & 5 & 6 & 7 \\
\hline $\begin{array}{l}\text { Initial } \mathrm{Pb} \\
\text { concentration } \\
(\mathrm{mg} / \mathrm{L})\end{array}$ & $\mathrm{X}_{3}$ & 50 & 100 & 150 & 200 & 250 \\
\hline $\begin{array}{l}\text { Addition of } \mathrm{Na}_{2} \mathrm{SO}_{4} \\
\text { (M) }\end{array}$ & $\mathrm{X}_{4}$ & 0.01 & 0.03 & 0.05 & 0.07 & 0.09 \\
\hline
\end{tabular}

\section{RESULTS AND DISCUSSION}

In this study the effect of process variables such as current density, initial lead concentration, $\mathrm{pH}$ and $\mathrm{Na}_{2} \mathrm{SO}_{4}$ concentration as a supporting electrolyte on the removal efficiency of lead were analyzed applying RSM. Current density and initial $\mathrm{pH}$ are an important operating factor influencing the performance of the EC process. While current density determines the coagulant dosage rate in electrocoagulation performance, $\mathrm{pH}$ determines the intermediates and the pathway of the reaction. Additionally, the solution conductivity plays a significant role during the electrocoagulation process. In this study $\mathrm{Na}_{2} \mathrm{SO}_{4}$ was used as a supporting electrolyte to increase solution conductivity and to reduce the electrical energy consumption of the electrocoagulation.

TABLE II: ANOVA TABLE FOR REMOVAL OF LEAD

\begin{tabular}{|c|c|c|c|c|c|}
\hline \multicolumn{6}{|l|}{ Analysis of Variance } \\
\hline Source & DF & Adj SS & Adj MS & F-Value & P-Value \\
\hline Model & 14 & 252,117 & 18,008 & 13,21 & 0,000 \\
\hline Linear & 4 & 186,955 & 46,739 & 34,29 & 0,000 \\
\hline A & 1 & 175,989 & 175,989 & 129,11 & 0,000 \\
\hline B & 1 & 4,148 & 4,148 & 3,04 & 0,089 \\
\hline C & 1 & 2,857 & 2,857 & 2,10 & 0,156 \\
\hline $\mathrm{D}$ & 1 & 3,962 & 3,962 & 2,91 & 0,096 \\
\hline Square & 4 & 58,082 & 14,521 & 10,65 & 0,000 \\
\hline$A \star A$ & 1 & 31,867 & 31,867 & 23,38 & 0,000 \\
\hline$B * B$ & 1 & 7,678 & 7,678 & 5,63 & 0,023 \\
\hline $\mathrm{C}^{\star} \mathrm{C}$ & 1 & 5,631 & 5,631 & 4,13 & 0,051 \\
\hline$D^{\star} \mathrm{D}$ & 1 & 0,040 & 0,040 & 0,03 & 0,866 \\
\hline 2-Way Interaction & 6 & 7,080 & 1,180 & 0,87 & 0,529 \\
\hline$A * B$ & 1 & 1,284 & 1,284 & 0,94 & 0,338 \\
\hline$A * C$ & 1 & 2,426 & 2,426 & 1,78 & 0,190 \\
\hline$A * D$ & 1 & 0,342 & 0,342 & 0,25 & 0,619 \\
\hline$B * C$ & 1 & 0,112 & 0,112 & 0,08 & 0,776 \\
\hline$B * D$ & 1 & 2,200 & 2,200 & 1,61 & 0,211 \\
\hline$C * D$ & 1 & 0,717 & 0,717 & 0,53 & 0,473 \\
\hline Error & 39 & $9 \quad 53,15$ & & 363 & \\
\hline Lack-of-Fit & 10 & 44,913 & 4,491 & 15,80 & 0,000 \\
\hline Pure Error & 29 & $9 \quad 8,24$ & & 284 & \\
\hline Total & 53 & 305,27 & & & \\
\hline
\end{tabular}

In Table II, A: Current Density, B: Initial pH; C: Initial Pb concentration; D: Addition of $\mathrm{Na} 2 \mathrm{SO} 4(\mathrm{M})$

Experiments were conducted in random order with two replications having 27 experiments in each replication and percentage removal of lead was obtained. The ANOVA (Analysis of variance) was carried for three hypothesis having four variable factors. In the first hypothesis the mean level of factors was maintained equal followed by hypothesis with mean levels differing from each other (at least one of them will differ from rest) and the last hypothesis was focused on studying the variable interaction effects on the response. The simulations were carried using MINITAB 17.0 statistical software and results are tabulated in Table II. From Table II on removal of lead it can be observed that the both linear and square terms are affected because their p-value is smaller than significant level- $\alpha$ ( $\mathrm{p}$-value $<0.05)$.

Due to the interaction terms were found unaffected on response, also initial lead and $\mathrm{Na}_{2} \mathrm{SO}_{4}$ concentrations, these unaffected terms are removed from ANOVA table. The Final ANOVA table that include the linear and square terms of the current density and $\mathrm{pH}$ were effecting the response are handled like in Table III.

TABLE III: FINAL ANOVA TABLE FOR REMOVAL OF LEAD

\begin{tabular}{lccccc} 
Analysis of Variance & & \\
Source & DF & Adj SS & Adj MS & F-Value & P-Value \\
Model & \multicolumn{7}{c}{431,485} & 57,871 & 38,43 & 0,000 \\
Linear & 2 & 180,136 & 90,068 & 59,81 & 0,000 \\
A & 1 & 175,989 & 175,989 & 116,86 & 0,000 \\
B & 1 & 4,148 & 4,148 & 2,75 & 0,103 \\
Square & 2 & 51,349 & 25,674 & 17,05 & 0,000 \\
A*A & 1 & 45,958 & 45,958 & 30,52 & 0,000 \\
B*B & 1 & 13,183 & 13,183 & 8,75 & 0,005 \\
Error & 49 & 73,791 & 1,506 & \\
Lack-of-Fit & 20 & 65,545 & 3,277 & 11,53 & 0,000 \\
Pure Error & 29 & 8,246 & 0,284 & & \\
Total & 53 & 305,276 & &
\end{tabular}

In Table III, A: Current Density, B: Initial pH

The coefficients of term placed in Final ANOVA Table are given in Table IV.

TABLE IV. THE CODED COEFFICIENTS OF EFFECTIVE TERMS

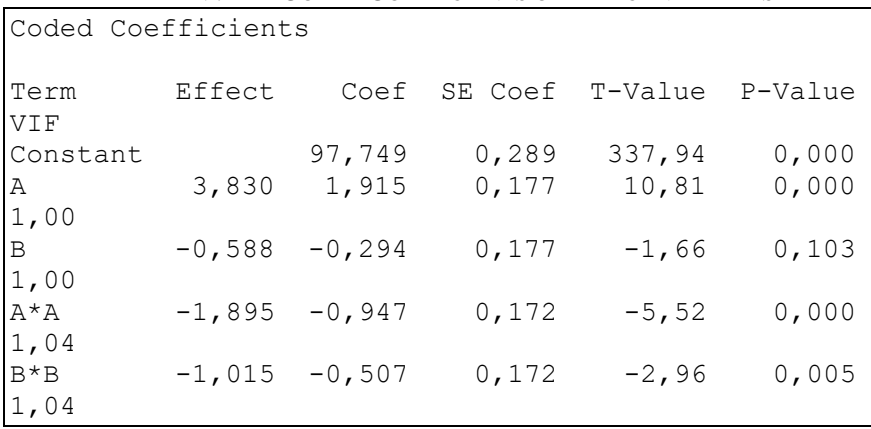

Therefore, the regression model with coded values is given in terms of current density and $\mathrm{pH}$ as follows in equation (7):

$$
\hat{y}=97.75+1.9148 x_{1}-0.294 x_{2}-0.9474 x_{1}^{2}-0.5074 x_{2}^{2}+\varepsilon
$$

In general, the coefficient of determination (R-square-adj.) explains the total variability accounted by the independent variables in regression model. In this model, R-Sq(adj) was found to be $73.9 \%$, which is adequate for explaining the variability. Also, the residuals of model have a Normal distribution (Fig. 2) with constant variance (Fig. 3). The surface plot of removal of lead as a function of current density and $\mathrm{pH}$ is shown in Fig. 4 and the contour plot is shown in Fig. 5. The nonlinearity of the model is clearly 
represented by the surface plot.

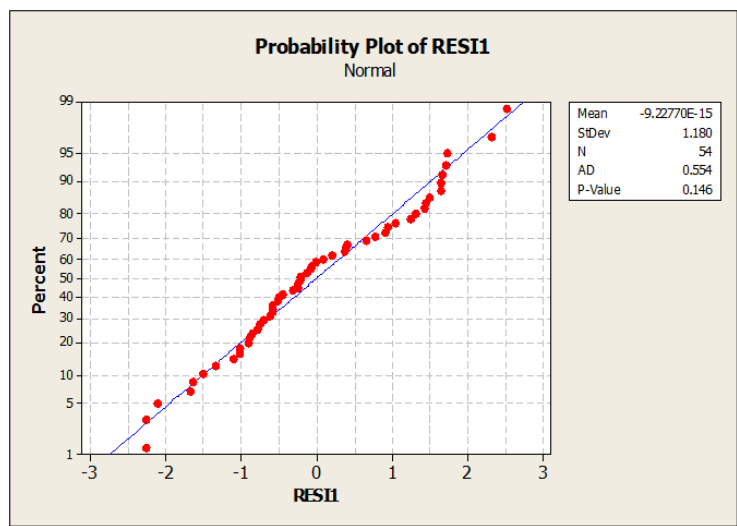

Fig. 2. The Normal probability plot.

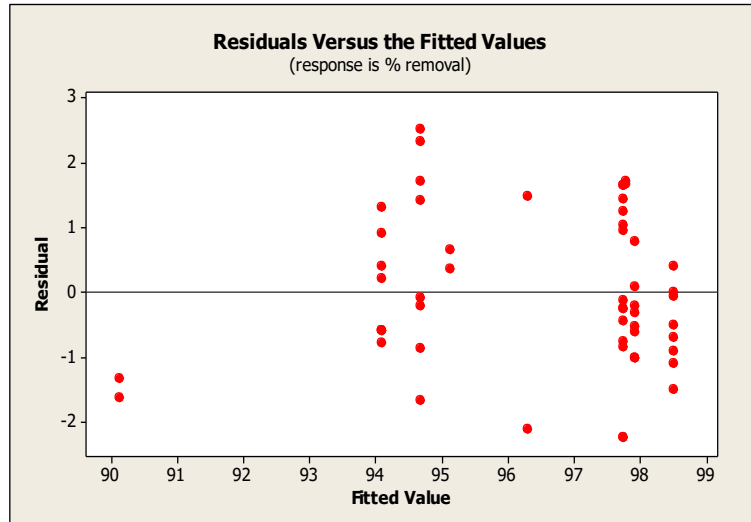

Fig. 3. The plot of residual versus predicted value.

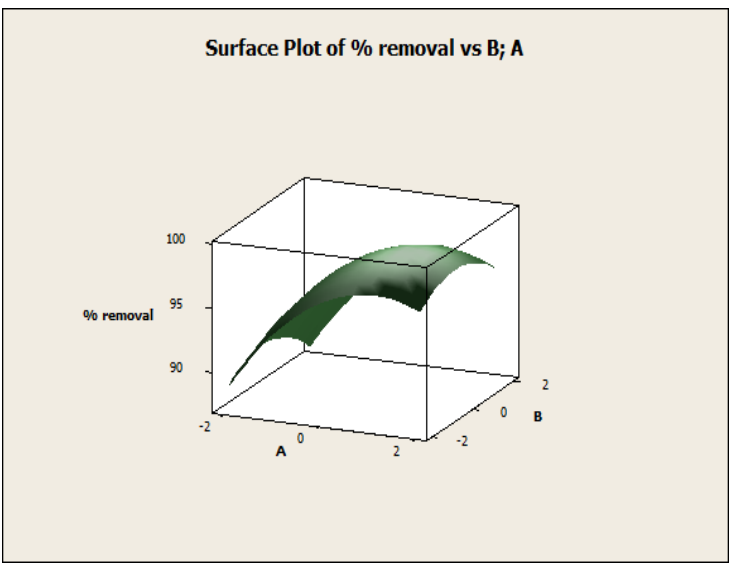

Fig. 4. The surface plot of removal of lead according to current density (A) and initial $\mathrm{pH}(\mathrm{B})$

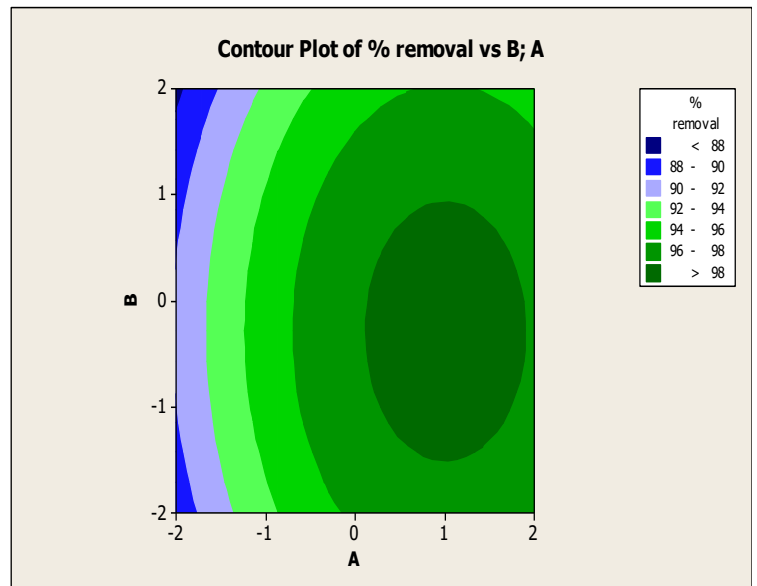

Fig. 5. The counter plot of removal of lead as a function of current density (A) and initial $\mathrm{pH}(\mathrm{B})$.

\begin{tabular}{|cc||cc|}
\hline Optimal & & $\mathrm{A}$ & $\mathrm{B}$ \\
$\mathrm{D}$ & $\mathrm{Hi}$ & 2.0 & 2.0 \\
0.89656 & Cur & {$[1.0147]$} & {$[-0.3027]$} \\
& Lo & -2.0 & -2.0 \\
\hline \% remova & & \\
Maximum & & \\
$\mathrm{y}=98.7587$ & & \\
$\mathrm{~d}=0.89656$ & & \\
& & & \\
& & & \\
\hline
\end{tabular}

Fig. 6. The optimum values of responses with coded values of factors.

The optimum value for removal of lead were obtained from Fig. 5 and 6 with coded value. The maximum value of lead removal was found to be $98.76 \%$ at the current density of $40 \mathrm{~mA} / \mathrm{cm}^{2}$ at $\mathrm{pH} 4.7$.

\section{CONCLUSION}

In this study, removal of lead from water using electrocoagulation method was achieved using a uniquely-designed batch electrocoagulation reactor. The empirical model, in terms of effective operational factors, such as initial $\mathrm{pH}$, current density, supporting electrolyte concentration and lead concentration was developed through Response Surface Methodology.

From the results a mathematical model correlating the effective factors like initial $\mathrm{pH}$, current density was developed. Interaction terms were not considered in the correlation as they have no statistically significant effect on the lead removal efficiency. The $R^{2}$ (adjusted) value of $74 \%$ is appropriate and acceptable to explain the total variation of response.

Current density has a linear effect while current density and initial $\mathrm{pH}$ have quadratic effects on the removal efficiency of lead. Lead removal efficiency reach a maximum value of $98.76 \%$ when the current density was $40 \mathrm{~mA} / \mathrm{cm}^{2}$ and initial $\mathrm{pH}$ was 4.7 .

\section{ACKNOWLEDGEMENTS}

This project was supported by Anadolu University Scientific Research Project Commission under Grant (1404F242)

\section{REFERENCES}

[1] S. Babel and T. A. Kurniawan, "Cr (VI) removal from synthetic wastewater using coconut shell charcoal and commercial activated carbon modified with oxidizing agents and/or chitosan", Chemosphere, vol. 54, no. 7, pp. 951-967, 2004.

[2] C. Chaffei, K. Pageau, A. Suzuki, H. Gouia, M. H. Ghorbal, and C. M. Daubresse, "Cadmium toxicity induced changes in nitrogen management in Lycopersicon esculentum leading to a metabolic safeguard through an amino acid storage strategy," Plant Cell Physiol, vol. 45, pp. 1681-1693, 2004.

[3] M. A. Barakat. "New Trends in Removing Heavy Metals from Industrial Wastewater," Arabian Journal of Chemistry, vol. 4, issue 4, pp. 361-377, 2011.

[4] M. Y. A Mollah, P. Morkovsky, J. A. G. Gomes, M. Kesmez, J. Parga, and D. L. Cocke. "Fundamentals, present and future perspectives of electrocoagulation.” J. Hazard. Mater., vol. B114, pp. 199-210, 2004.

[5] E. Bazrafshan, L. Mohammadi, A. Ansari-Moghaddam, and A. H. Mahvi, "Heavy metals removal from aqueous environments by 
electrocoagulation process- a systematic review," J. Environ. Health. Sci., vol. 13, pp. 1-16, 2015.

[6] A. Aygün, "Treatment of wastewater form reactive and dispers dye bathes in textile industry by electrocoagulation process: Optimization by response surface methodology," master of Thesis, Selcuk Üniversity, Konya, 2012.

[7] H. Turkyilmaz, "Optimization of removal of lead ions by batch adsorption process with response surface methodogy," master of Thesis, Suleyman Demirel Üniversity, Isparta, 2011.

[8] W. H. Hines and D. C. Montgomery, Probability and Statistics in Engineering and Management Science, 3rd ed. Wiley, New York, 1990.

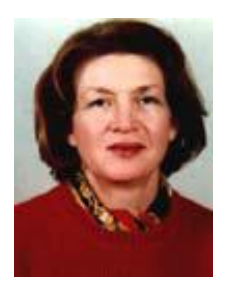

Ulker Bakir Ogutveren has graduated from Gazi University, department of Chemical Engineering in 1972. She achieved the professor degree in 1998, in Department of Environmental Engineering. She is currently, professor at Anadolu University, Department of Environmental Engineering. She dedicated her life to teaching in the field of environmental science and technology. Her research spans, industrial water pollution control, water pollution control and electrochemical applications. She has directed and supervised numerous research studies and projects in the field of wastewater management and industrial pollution control.

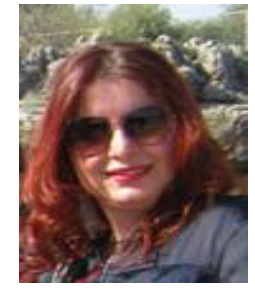

Umran Tezcan Un graduated from Department of Chemical Engineering, Anadolu University in 1992 and achieved to study environmental engineering a Anadolu University. She is currently a professor at Anadolu University, Department of Environmental Engineering. She has 26 years of teaching and research experience in the field of environmental science and technology. Her research spans are industrial pollution control, water treatment and electrochemical treatment methods. She has directed and supervised numerous research studies and projects in the field of wastewater management and industrial pollution control

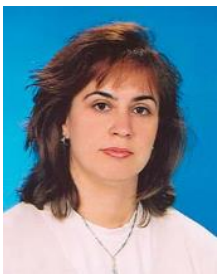

Nihal Erginel graduated from Department of Industrial Engineering, Anadolu University in 1988. She is currently a professor at Anadolu University, Department of Industrial Engineering. She has 25 years of teaching and research experience in the field of industrial engineering. Her research spans are experimental desing and analysis, quality control, statistical analysis. She has directed and supervised numerous research studies and projects in the field of her area. 